\title{
Influence of Heat Treatment on Hot-rolled Sheet Forming of Ti-6Al-4V Alloy
}

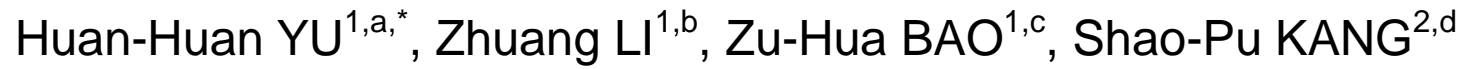 \\ ${ }^{1}$ School of Materials Science and Engineering, Shenyang Aerospace University, Shenyang 110136, \\ Liaoning, China \\ ${ }^{2}$ Great Wall Motor Company Limited, Baoding 071000, Hebei, China \\ ayuhuan_v@163.com, bizhuang20047@163.com, 'c1002941549@qq.com, dksp1989@163.com \\ ${ }^{*}$ Corresponding author
}

Keywords: Solution Heat Treatment, Aging, Ti-6Al-4V Alloy, Erichsen Value, a Phase.

\begin{abstract}
Solution heat treatment and subsequent precipitation aging operations of Ti-6Al-4V alloy were conducted, and erichsen test was performed. Detailed microstructure was carefully observed by light optical microscopy (LOM). Influence of heat treatment on hot-rolled sheet forming of Ti-6Al-4V alloy was investigated. The results showed that the microstructure of Ti-6Al-4V alloy consists of two phases $(\alpha-\beta)$. The grain size of primary $\alpha$ phase augmented and second- $\alpha$ phase grew with increasing aging temperature. A relatively high aging temperature of $580^{\circ} \mathrm{C}$ leads to sufficient coarsening of the microstructure. The hardness decreases with increasing aging temperature. However, erichsen value reaches the maximum value of $4.5 \mathrm{~mm}$ for aging treatment at $580^{\circ} \mathrm{C}$. Erichsen value increases with increasing aging temperature, this is attributed to the fact that the change of $\alpha$ phase from finely dispersed particles to coarsening. The cold-forming properties of Ti-6Al-4V alloy were improved by increasing aging temperature.
\end{abstract}

\section{Introduction}

Titanium alloys are very attractive not only for aerospace application but also for process engineering, automotive, medical and sport applications owing to the high specific bending stiffness and strength, combined with corrosionandcreepresistance [1]. Due to their excellent performances, titanium alloys have been widely used in making many key aerospace components, such as engine compressor, blade, bearing bulkhead [2-4]. Titanium alloys can be strengthened by a series of heat treatment. For example, the tensile strength of Ti-6Al-4V alloy can be improved from 900-1000 MPa to 1100-1200 MPa by annealing [5, 6].

Ti-6Al-4V alloy has relatively poor room-temperature shaping and forming characteristics (compared to steel and aluminum). Therefore, currently, very limited research is published in the field of direct forming of Ti-6Al-4V. In fact, it is necessary to make some research efforts in sheet metal forming of, e.g. Ti-6Al-4V [7]. Through different heat treatment methods, different microstructures could be produced. It is very important to understand the deformation characteristics and the relationship between microstructure and the properties.

In this study, solution heat treatment and subsequent precipitation aging operations were conducted, and erichsen test was performed. Detailed microstructure was carefully observed by light optical microscopy (LOM). Influence of heat treatment on hot-rolled sheet forming of Ti-6Al-4V alloy was investigated.

\section{Experimental}

A Ti-6Al-4V alloy was chosen as the testing material in this work. It was forged into a piece of $100 \times 100 \times 30 \mathrm{~mm}$ thick slab. A reheating temperature of $1100^{\circ} \mathrm{C}$, a start rolling temperature of $1000^{\circ} \mathrm{C}$, were applied during rolling process down to a thickness of $10 \mathrm{~mm}$. Some blocks $(20 \mathrm{~mm} \times 20 \mathrm{~mm} \times 10 \mathrm{~mm})$ were machined, they were then hot-rolled down to $1 \mathrm{~mm}$.

Ti-6Al-4V alloys were solution-treated at $1000^{\circ} \mathrm{C}$, for $30 \mathrm{~min}$, and then air cooled. Aging 
treatment for 12 hour at $480^{\circ} \mathrm{C}, 530^{\circ} \mathrm{C}, 580^{\circ} \mathrm{C}$ was conducted, respectively, followed by air cooling. The processing schedule of Ti-6Al-4V alloy is shown in Tab.1.

Tab.1 The processing parameters during aging treatment

\begin{tabular}{|c|c|c|c|c|}
\hline Specimen no & Aging temp. $/{ }^{\circ} \mathrm{C}$ & Aging time / h & Erichsen value / mm & HV10 \\
\hline 11 & \multirow{3}{*}{480} & \multirow{3}{*}{12} & 4.13 & 510.45 \\
\hline 12 & & & 4.05 & 516.40 \\
\hline 13 & & & 4.10 & 512.25 \\
\hline 21 & \multirow{3}{*}{530} & \multirow{3}{*}{12} & 4.22 & 512.35 \\
\hline 22 & & & 4.30 & 506.25 \\
\hline 23 & & & 4.26 & 508.83 \\
\hline 31 & \multirow{3}{*}{580} & \multirow{3}{*}{12} & 4.50 & 470.82 \\
\hline 32 & & & 4.48 & 475.85 \\
\hline 33 & & & 4.52 & 472.33 \\
\hline
\end{tabular}
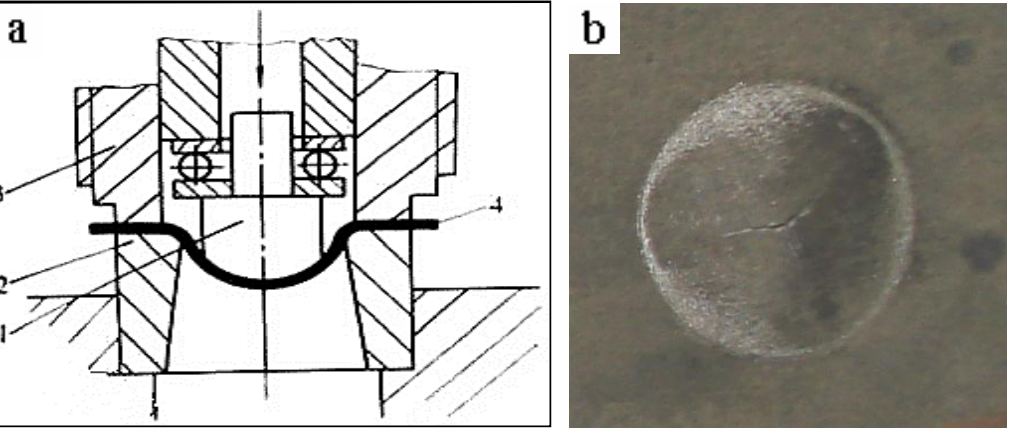

1-terne die; 2-cavity die 3-clamping ring 4-specimen (a) test equipment; (b) test specimen

Fig.1 Schematic illustration of erichsen test

Erichsen test was performed. Schematic illustration of erichsen test equipment and the specimen are shown in Fig. 1, respectively.

Transverse sections of the specimens for light optical microscopy (LOM) were polished and etched with $4 \%$ nital. The microstructure was investigated further by scanning electron microscopy (SEM) using a QUANTA600 microscope. Mean value of Vickers (HV30) hardness of three specimens were collected.

\section{Results and Discussion}

\section{Microstructures}

The micrographs of the specimens aging treatment at $4800^{\circ} \mathrm{C}, 530^{\circ} \mathrm{C}$ and $580^{\circ} \mathrm{C}$ using a 12 -h aging time are shown in Fig. 2.

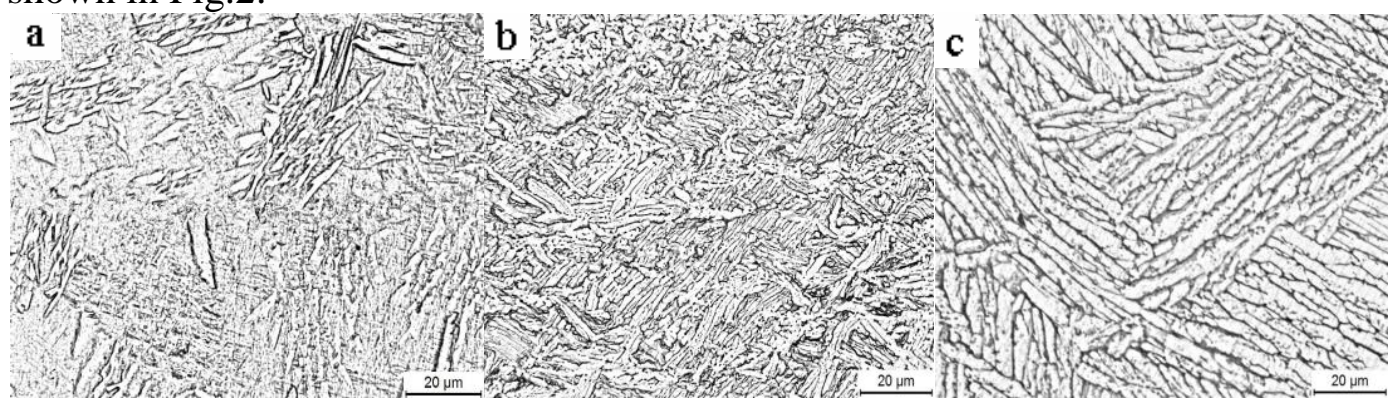

$$
\text { (a) } 480{ }^{\circ} \mathrm{C} \text {; (b) } 530^{\circ} \mathrm{C} \text {; (c) } 580^{\circ} \mathrm{C}
$$

Fig.2 Optical micrographs of specimens after different aging treatment 
After solution heat treatment and subsequent precipitation aging, the microstructure consists of two phases $(\alpha-\beta)$. It can be found with a bimodal microstructure, i.e., primary $\alpha$ grains surrounded by $\alpha+\beta$ lamellar matrix.

\section{Erichsen and Hardness Test}

Erichsen test curves of three specimens at different aging treatment are shown in Fig.3, respectively. Tab. 1 lists the erichsen and hardness test results of the specimens. The average values of the erichsen and hardness test of three specimens are shown in Fig. 4.

In Fig. 3 and Fig. 4 and Tab.1, erichsen value increases with increasing aging temperature, it reaches the maximum value of $4.5 \mathrm{~mm}$ for aging treatment at $580^{\circ} \mathrm{C}$. On the contrary, the hardness reaches the highest value $(513)$ at the aging temperature of $480^{\circ} \mathrm{C}$, and it decreases with increasing aging temperature.

\section{Evolvement of the Microstructure during Heat Treatment}

The heat treatment of titanium alloys involves solution treatment followed by aging at three temperatures. This treatment results in formation of finely dispersed $\alpha$ particles in the retained $\beta$. Ti-6Al-4V is a $\alpha+\beta$ alloy, because its microstructure contains a mixture of $\alpha$ phase with a hexagonal closed packed (hcp) crystal structure and $\beta$ phase with a body centered cubic (bcc) structure [8]. The heat treatment affects hot-rolled sheet forming of Ti-6Al-4V alloy. Solution treatment followed by aging at $480^{\circ} \mathrm{C}$ to $580^{\circ} \mathrm{C}$ precipitates $\alpha$, resulting in a fine mixture of $\alpha$ and $\beta$ in a matrix of retained or transformed $\beta$ phase.

The mixture of $\alpha+\beta$ transformed from $\beta$ phase is fine and dispersed due to relatively low temperature when the specimens were aging treated at $480^{\circ} \mathrm{C}$ (Fig. 2 (a)). Primary $\alpha$ grains increases with increasing aging temperature and second $\alpha$ phase grew and spheroidized gradually with increasing aging temperature (Fig. 2 (b)). A relatively high aging temperature of $580^{\circ} \mathrm{C}$ leads to sufficient coarsening of the microstructure (Fig. 2 (c)).
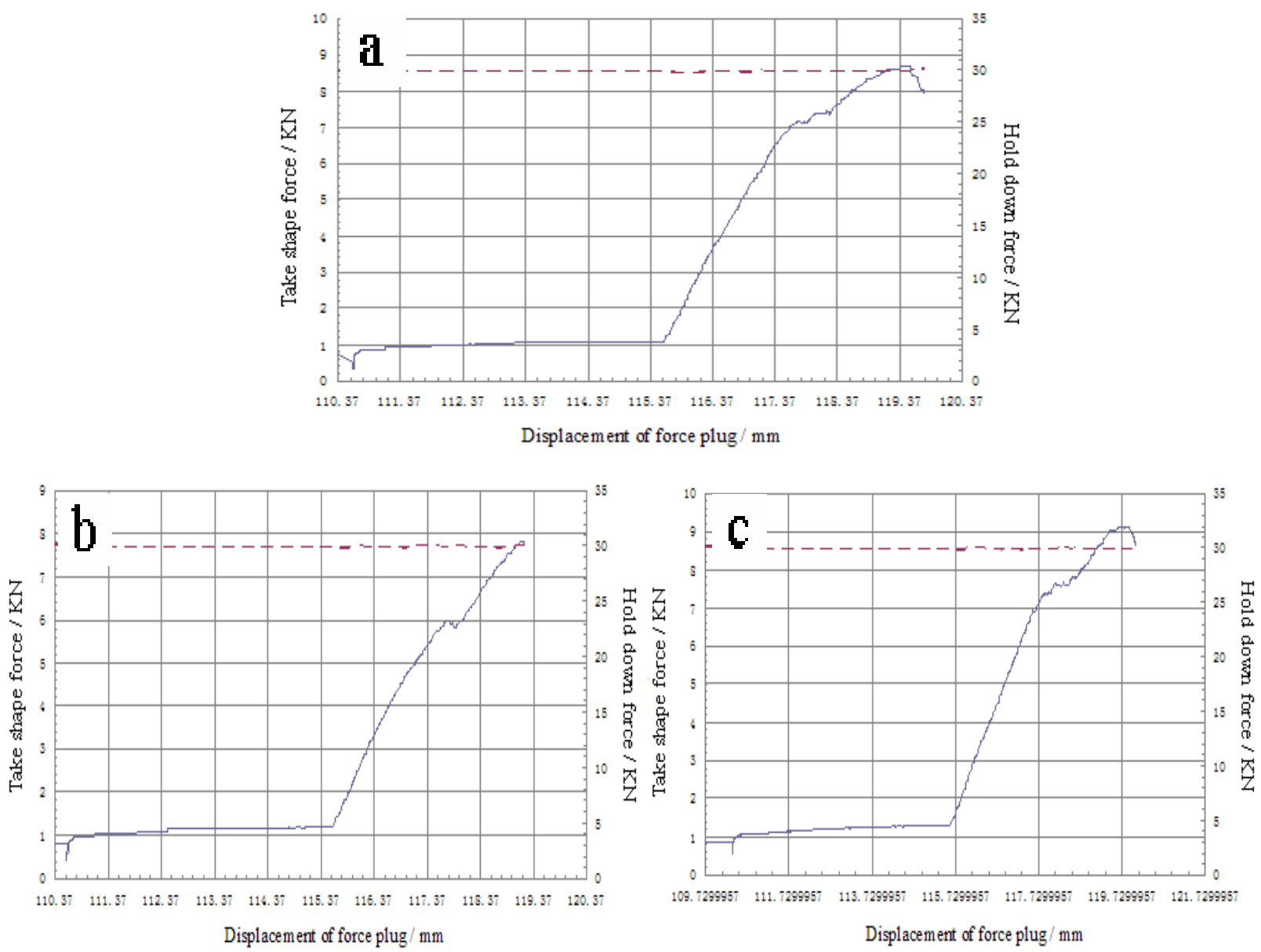

(a) $480^{\circ} \mathrm{C}$; (b) $530^{\circ} \mathrm{C}$; (c) $580^{\circ} \mathrm{C}$

Fig.3 Erichsen test curves of three specimens at different aging temperature 


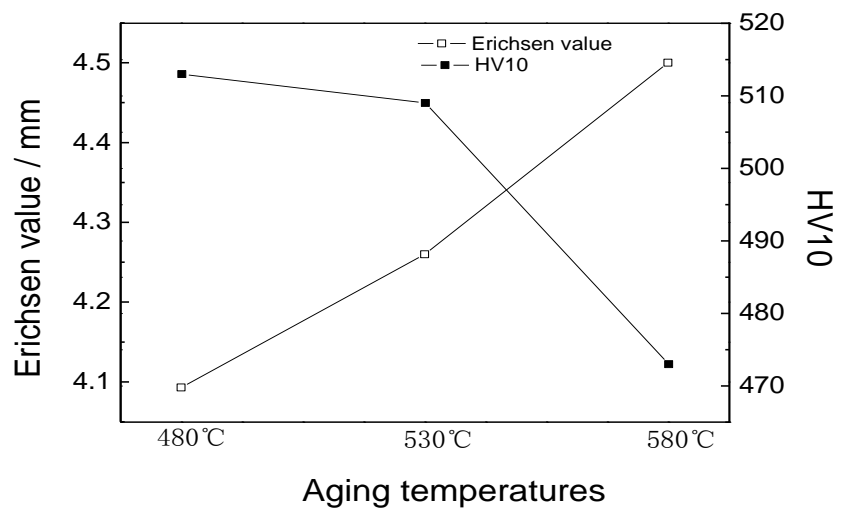

Fig.4 The average values of the erichsen and hardness test

The heat treatment provides most of the strengthening. Through solution treatment and different aging methods, microstructures with different shapes, sizes, and distributions of $\alpha$ and $\beta$ phases could be produced. Different microstructures would in turn lead to different macroscopic hardness value. Therefore, the hardness reaches the highest value after aging. On the other hand, the hardness has changed with the aging temperature. It decreases with increasing aging temperature because coarsening decreases the strength of the resulting product. Erichsen value increases with increasing aging temperature, this is attributed to the fact that the change of $\alpha$ phase from finely dispersed particles to coarsening.

\section{Conclusions}

(1) The microstructure of Ti-6Al-4V alloy consists of two phases $(\alpha-\beta)$. The grain size of primary $\alpha$ phase augmented and second- $\alpha$ phase grew. A relatively high aging temperature of $580^{\circ} \mathrm{C}$ leads to sufficient coarsening of the microstructure.

(2) The heat treatment affects hot-rolled sheet forming of Ti-6Al-4V alloy. The hardness decreases with increasing aging temperature. However, erichsen value reaches the maximum value of $4.5 \mathrm{~mm}$ for aging treatment at $580^{\circ} \mathrm{C}$. The cold-forming properties of Ti-6Al-4V alloy were improved by increasing aging temperature.

(3) Erichsen value increases with increasing aging temperature, this is attributed to the fact that the change of $\alpha$ phase from finely dispersed particles to coarsening.

\section{Acknowledgement}

This work was financially supported by the National Natural Science Foundation of China (51004037), Shenyang City Application Basic Research Project (No. F13-316-1-15) and State Key Laboratory Opening Project of Northeastern University (12SYS05).

\section{References}

[1]F. Warchomicka, C. Poletti, M. Stockinger, Study of the hot deformation behaviour in Ti-5Al-5Mo-5V-3Cr-1Zr, Mater. Sci. Eng., A. 528 (2011) 8277-8285.

[2]Y.M. Arisoy, T. Özel, Prediction of machining induced microstructure in Ti-6Al-4V alloy using 3-D FE-based simulations: Effects of tool micro-geometry, coating and cutting conditions, J. Mater. Process. Technol. 220 (2015) 1-26.

[3]Z.L. Zhao, H. Li, M.W. Fu, H.Z. Guo, Z.K. Yao, Effect of the initial microstructure on the deformation behavior of Ti60 titanium alloy at high temperature processing, J. Alloys Compd. 617 (2014) 525-533. 
[4]T. Thepsonthi, T. Oze, 3-D finite element process simulation of micro-end milling Ti-6Al-4V titanium alloy: Experimental validations on chip flow and tool wear, J. Mater. Process. Technol. 221 (2015) 128-145.

[5]D.P. Davies, S.L. Jenkins, Influence of forming method on the tensile and fatigue properties of Ti-6Al-4V sheet for helicopter erosion shield applications, Mater Des. 33 (2012) 254-263.

[6]S. W. Kim, J. H. Kim, Y.H.Song, J.K.Hong, Y.T. Hyun, J. T. Yeom, Deformation characteristics of Ti-6Al-4Fe alloys with enhanced high temperature ductility, Mater. Sci. Eng., A. 559 (2013) 96-100.

[7]J.H. Kim, C.H. Lee, J.K. Hong, J.H. Kim, J.T. Yeom, Effect of surface treatment on the hot forming of the high strength Ti-6A1-4V fastener, Mater. Trans. 50 (2009) 2050-2056.

[8]N. Biswas, J.L. Ding , V.K. Balla , D.P. Field, A. Bandyopadhyay, Deformation and fracture behavior of laser processed dense and porous Ti6Al4V alloy under static and dynamic loading, Mater. Sci. Eng., A. 549 (2012) 213-221. 